\title{
Targeting the Lnc-OPHN1-5/androgen receptor/hnRNPA1 complex increases Enzalutamide sensitivity to better suppress prostate cancer progression
}

\author{
Meng Zhang ${ }^{1,2,3,5}$, Yin Sun ${ }^{2,5}$, Chi-Ping Huang ${ }^{4,5}$, Jie Luo ${ }^{2}$, Li Zhang ${ }^{1}$, Jialin Meng ${ }^{1}$, Chaozhao Liang (iD ${ }^{1 凶}$ and \\ Chawnshang Chang (iD ${ }^{2,4 凶}$
}

(C) The Author(s) 2021

\begin{abstract}
Long non-coding RNAs (IncRNAs) have been found to play critical roles in regulating gene expression, but their function in translational control is poorly understood. We found Inc-OPHN1-5, which lies close to the androgen receptor (AR) gene on chromosome X, increased prostate cancer (PCa) Enzalutamide (Enz) sensitivity via decreasing AR protein expression and associated activity. Mechanism dissection revealed that Inc-OPHN1-5 interacted with AR-mRNA to minimize its interaction with the RNA binding protein (RBP) hnRNPA1. Suppressing Inc-OPHN1-5 expression promoted the interaction between AR-mRNA and hnRNPA1, followed by an increase of ribosome association with AR-mRNA and translation. This effect was reversed by increasing Inc-OPHN1-5 expression. Consistently, the in vivo mice model confirmed that knocking down Inc-OPHN1-5 expression in tumors significantly increased the tumor formation rate and AR protein expression compared with the control group. Furthermore, knocking down hnRNPA1 blocked/reversed shlnc-OPHN1-5-increased AR protein expression and re-sensitized cells to Enz treatment efficacy. Evidence from Enz-resistant cell lines, patient-derived xenograft (PDX) models, clinical samples, and a human PCa study accordantly suggested that patients with low expression of Inc-OPHN1-5 likely have unfavorable prognoses and probably are less sensitive to Enz treatment. In summary, targeting this newly identified Inc-OPHN1-5/AR/hnRNPA1 complex may help develop novel therapies to increase Enz treatment sensitivity for suppressing the PCa at an advanced stage.
\end{abstract}

Cell Death and Disease (2021)12:855 ; https://doi.org/10.1038/s41419-021-03966-4

\section{INTRODUCTION}

Prostate cancer ( $\mathrm{PCa}$ ) is the most frequently diagnosed malignancy among men in the western world [1-4]. The androgendeprivation therapy (ADT) with recently developed anti-androgen Enzalutamide (Enz) is frequently followed by the development of ADT-resistance. An important molecular mechanism of ADTresistance is the continued activation of the androgen receptor (AR) protein. Identifying novel biological mechanisms underlying this aberrant AR activation holds great promise to improve the treatment of castration-resistant prostate cancer (CRPC) patients.

Previous studies have shown mutations, genomic amplifications, and deletions, which were commonly found in the AR gene during the development of CRPC, ultimately contributed to the continued and enhanced AR activity $[5,6]$. More recent studies indicated that enhancers located much farther away on the linear sequence might activate $A R$ transcription through chromatin looping to drive the progression of metastatic CRPC [7]. Simultaneously, the altered chromatin landscape around the AR locus may also change the expression of resident genes, including long non-coding RNAs (IncRNAs).
The IncRNAs are RNA transcripts of more than $200 \mathrm{nt}$ long but have little ability to encode proteins. More recently, numerous IncRNAs have been annotated, and their functions in regulating biological procedures have begun to be uncovered [8-10]. The IncRNAs could be associated with chromatin-modifying proteins, such as the polycomb repressive complexes (PRC2), to regulate chromatin states $[11,12]$. Accumulating evidence found that IncRNAs are able to regulate cellular processes via posttranslational mechanisms $[13,14]$, in addition to their ability in regulating the mRNA translation by interacting with RNA binding proteins (RBPs), such as hnRNPA1, thus influencing the level of the encoded protein and biological functions of downstream genes $[15,16]$. Based on these regulatory mechanisms, IncRNAs have been shown to play pivotal roles in human cancer development.

Here, we report a novel IncRNA, Inc-OPHN1-5, which was located one megabase (MB) $3^{\prime}$ of AR on chromosome $X$, and it influenced Enz treatment sensitivity via decreasing AR mRNA translation, thus decreased AR protein level and transcriptional activity. Targeting this newly identified Inc-OPHN1-5/AR/ hnRNPA1 complex with silenced hnRNPA1 (shhnRNPA1) led to

\footnotetext{
'Department of Urology, The First Affiliated Hospital of Anhui Medical University, Institute of Urology, \& Anhui Province Key Laboratory of Genitourinary Diseases, Anhui Medical University, Hefei, China. ${ }^{2}$ George Whipple Lab for Cancer Research, Departments of Pathology, Urology, Radiation Oncology, The Wilmot Cancer Institute, University of Rochester Medical Center, Rochester, NY, USA. Institute of Urology, Shenzhen University, Shenzhen, China. ${ }^{4}$ Department of Urology, China Medical University, Taichung, Taiwan. ${ }^{5}$ These

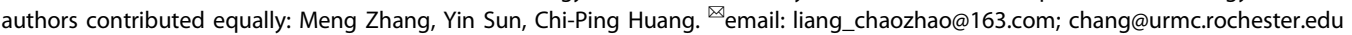
Edited by S. Tait
}

Received: 28 November 2019 Revised: 14 June 2021 Accepted: 21 June 2021

Published online: 20 September 2021 
increasing Enz treatment sensitivity for greater suppression of CRPC progression.

\section{MATERIALS AND METHODS \\ Human samples}

We collected the formalin-fixed, paraffin-embedded (FFPE) samples from 75 prostate cancer patients with complete follow-up features from the Department of Urology, The First Affiliated Hospital of Anhui Medical University. The biochemical recurrence (or recurrence-free survival) was defined as the prostate-specific antigen (PSA) level higher than $0.2 \mathrm{ng} / \mathrm{mL}$ determined 2-4 months after radical prostatectomy, and confirmation tests were performed to prove the continued elevation of PSA levels. The ethics of our study were approved by The Committee on Medical Ethics of The First Affiliated Hospital of Anhui Medical University (J2019911 \& PJ 20210214). The tissues were used to extract RNA (Cat. 73504, RNeasy FFPE Kit, Hilden, Germany) for Inc-OPHN1-5 quantification.

\section{Cell lines, inhibitors, and antibodies}

The information of cell lines used in current work was demonstrated in our previous work [17], including C4-2R (derived from C4-2 cells and resistant to Enz treatment) and the C4-2BR (derived from C4-2B cells and resistant to Enz treatment) cells, which were cultured in RPMI media supplied with 10 and $20 \mu \mathrm{M} \mathrm{Enz}$, respectively. Antibodies of GAPDH (sc47724), a-Tubulin (sc-134241), AR (N-20), hnRNPA1 (sc-32301), hnRNPA/B (sc-376411), hnRNPK (sc-28380), and HUR (sc-5261) were purchased from Santa Cruz Biotechnology (Santa Cruz Biotechnology, TX, USA). We also purchased an AR antibody (3202S) from Cell Signaling Technology (Cell Signaling Technology, MA, USA). The Inc-OPHN1-5 and AR-specific biotins were purchased from Integrated DNA Technologies Company (Integrated DNA Technologies, CA, USA).

\section{Plasmids and lentivirus packaging}

The plasmids used in the current work were listed in Table S1, and they were packaged with the psAX2 packaging plasmid and PMD2G envelope plasmid and co-transfected into 293T cells via the standard calcium chloride transfection method. After $48 \mathrm{~h}$, we collected the lentivirus supernatants and kept them in $-80 \mathrm{C}^{\circ}$ freezer for future use. For the viruses that were generated by pLKO.1 vector-based plasmids, cells were selected for stable expression with puromycin $(1.5 \mu \mathrm{g} / \mathrm{mL}$ ) (CAS № $58-58-$ 2, Cayman, MI, USA).

\section{Western blotting (WB) and mouse mammary tumor virus (MMTV)-luciferase assay}

Briefly, we used cell lysis buffer to lyse collected cells, and after quantification and loading-mixed boiling processes, equal weights of proteins were separated on $10 \%$ sodium dodecyl sulfate/polyacrylamide gel electrophoresis gel and then transferred onto PVDF membranes (Millipore, MA, USA). We used 5\% milk to block the membrane for $1 \mathrm{~h}$ and then incubated it with the specific primary antibodies overnight. After washing, the blots were incubated with HRP-conjugated secondary antibodies and then visualized using the ECL system (Thermo Fisher Scientific, Rochester, NY, USA). The AR activity was determined by MMTVluciferase assay according to our previous work $[18,19]$.

\section{MTT assay and ethynyl-2-deoxyuridine (EdU) staining}

Cells were mixed with RPMl media, and we added $500 \mu$ media mix containing 5000 cells/well into the 24-well plates. Before collecting, we added $50 \mu \mathrm{L}$ MTT reagent $(5 \mathrm{mg} / \mathrm{mL}$ MTT in PBS, Amresco, OH, USA) to each well and incubated at $37^{\circ} \mathrm{C}$ for $2 \mathrm{~h}$. After removing supernatants, we added $1 \mathrm{~mL}$ dimethyl sulfoxide (Amresco, OH, USA) to dissolve the crystals. The optical density (OD) was determined at a wavelength of $570 \mathrm{~nm}$ on a microplate reader. The effects of Inc-OPHN1-5 on PCa cell Enz sensitivity were also tested by EdU incorporation assay using Cell-Light ${ }^{\mathrm{TM}}$ EdU Apollo 567 In Vitro Imaging Kit (RiboBio, Guangzhou, China). Briefly, the EdU was added to each well with a final concentration of $50 \mu \mathrm{M}$. After $2 \mathrm{~h}$ incubation, cells were fixed with $4 \%$ paraformaldehyde at room temperature (RT). We used PBST [phosphate buffer saline (PBS) with $0.1 \%$ Triton X-100] to wash each well 3 times, followed by $1 \times$ Apollo solution incubating for $30 \mathrm{~min}$ at RT away from light. Finally, the cell nuclei were stained with $1 \times$ Hoechst for $30 \mathrm{~min}$, and the stained cells were visualized by fluorescence microscopy (Olympus, Tokyo, Japan).

\section{Ribosome-enriched RNA extraction and nucleus-cytoplasm fraction}

C4-2 cells $(2 \times 107)$ were collected, and centrifuged for $5 \mathrm{~min}$ at $900 \times \mathrm{g}$, and washed twice with pre-chilled $0.15 \mathrm{M} \mathrm{NaCl}$. The detailed steps followed T Masse et al.'s [20] study. We resuspended these cells in $2 \mathrm{~mL}$ of buffer $\left(0.25 \mathrm{M} \mathrm{KCl}, 0.005 \mathrm{M} \mathrm{MgCl}_{2}, 0.014 \mathrm{M}\right.$ 2-mercaptoethanol (2-ME), $0.05 \mathrm{M}$ Tris- $\mathrm{HCl} / \mathrm{pH} 7.4,0.25 \mathrm{M}$ sucrose) and lysed by adding $70 \mu \mathrm{L}$ of $20 \%$ Nonidet P-40 solution [21]. After $15 \mathrm{~min}$ at $4{ }^{\circ} \mathrm{C}$, we removed the nuclei by centrifuging for $10 \mathrm{~min}$ at $900 \times g$. Then we removed the mitochondria by high-speed centrifugation at $12,500 \times g$ for $10 \mathrm{~min}$. We adjusted the supernatant to $0.5 \mathrm{M} \mathrm{KCl}$ and layered on to $2 \mathrm{~mL}$ cushion ( $1 \mathrm{M}$ sucrose made in $0.5 \mathrm{M} \mathrm{KCl}, 0.005 \mathrm{M} \mathrm{MgCl}_{2}, 0.05 \mathrm{M}$ Tris- $\mathrm{HCl} / \mathrm{pH}$ 7.4). Ribosomes were pelleted by centrifugation for $4 \mathrm{~h}$ at $4{ }^{\circ} \mathrm{C}$ and $260,000 \times g$. We resuspended the pellets with $500 \mu \mathrm{L}$ Trizol (Invitrogen, CA, USA) for the next step of the RNA extraction process.

Cytoplasmic and nuclear RNAs were purified from C4-2 cells using a cytoplasmic and nuclear RNA purification kit (Norgen Biotek, ON, Canada). Briefly, $400 \mu \mathrm{L}$ lysis buffer was added to the C4-2 cell pellet and incubated on ice for $10 \mathrm{~min}$, and then centrifuged for $15 \mathrm{~min}$ at $14,000 \mathrm{rpm}$ to separate the cellular fractions. The supernatant comprised a cytoplasmic fraction, while the pellet comprised the nuclear component. We mixed these two tubes with $800 \mu \mathrm{L} 1.6 \mathrm{M}$ sucrose solution and carefully layered them on the surface of 2 separate $1000 \mu \mathrm{L}$ sucrose solution tubes. We centrifuged the two fractions at $14,000 \mathrm{rpm}$ for $15 \mathrm{~min}\left(4^{\circ} \mathrm{C}\right)$, and then the cytoplasm was obtained from the top layer of the sucrose cushion. We purified the cytoplasm RNA according to the protocol of the Norgen kit. We obtained the nuclear pellet from the bottom of the tube and used $400 \mu \mathrm{L} 1 \times$ PBS to wash it. The nuclear pellet was collected after another centrifugation process at $14,000 \mathrm{rpm}$ for $5 \mathrm{~min}$, and then the nuclear RNA was purified according to the protocol of the Norgen kit. The purified RNA was re-suspended in $500 \mu \mathrm{L}$ Trizol (Invitrogen).

\section{RNA immunoprecipitation}

We added $1 \mathrm{~mL}$ RNase-free cell lysis buffer to the plates of cells, along with $1 \mu \mathrm{L}$ RNase inhibitor (cat\# M0307S, NEB, MA, USA). After storage in $-80^{\circ} \mathrm{C}$ freezer for $30 \mathrm{~min}$, the cell lysates were centrifuged at $14,000 \mathrm{rpm}$ for $15 \mathrm{~min}$ to collect the supernatants. Then, the cell lysates were mixed with Streptavidin-coupled Dynabeads (Invitrogen) and incubated at $4{ }^{\circ} \mathrm{C}$ for $2 \mathrm{~h}$ with gentle rotation. Each of the lysates was divided into three parts, including input, control, and test groups. The antibodies or biotins were added to each element as needed. After $12 \mathrm{~h}$ incubation, we added $20 \mu \mathrm{L}$ Streptavidin-coupled Dynabeads to each tube and rotated for $1 \mathrm{~h}$. These beads were washed by RIP buffer 10 times and re-suspended in $500 \mu \mathrm{L}$ Trizol for RNA extraction. The RNA extraction and reverse transcriptionpolymerase chain reaction (RT-PCR) protocol were performed according to our previous work [22].

\section{Animal model and patient-derived xenografts}

The ethics of animal studies were approved by the Ethics Committee of Anhui Medical University. The 6-week-old male NOD CRISPR Prkdc $112 \mathrm{r}$ Gamma triple-immunodeficient mice (NCG) were purchased from GemPharmatech Co., Ltd (Nanjing, China) [23]. The C4-2 cells, which expressed pLKO.1 or shlnc-OPHN1-5, were obtained by stable clone selection procedures. Cells $(3 \times 106)$ mixed with Matrigel $(1: 1, v / v$, Cat. 356234, BD, USA) were subcutaneously injected into the NCG male mice at 6 weeks of age (randomly assigned into two groups). The mouse body weights and tumor volumes were monitored weekly, and the tumor weights were determined after sacrifice [24]. In addition, the patient-derived xenograft tissues (PDX) were gifts from the University of MD Anderson (USA) and subcutaneously injected into the NOD-SCID male mice as above. After a long-term treatment with Enz or vehicle, the tumor tissues were obtained for RNA extraction, immunohistochemical (IHC), and RT-PCR process.

\section{IHC staining}

We obtained the tumor tissues from each mouse and embedded them in paraffin. These samples were cut into $5 \mu \mathrm{m}$ thick slices and dehydrated with xylene. We stained the AR (\#8428, Cell Signaling Technology) and hnRNPA1 (Abcam, Cambridge, UK) antibodies at $4{ }^{\circ} \mathrm{C}$ incubator overnight and then incubated with the secondary antibody at RT for $1 \mathrm{~h}$. The detailed steps of the IHC process and the score quantification were described in our previous work $[25,26]$. The IHC scores were determined by $P \times I$ [positively stained cells $(P \%) \times$ the intensity $(I)$, range from $1=$ weak; $2=$ moderate to 3 = strong. IHC score $\leq 300$.] 
A

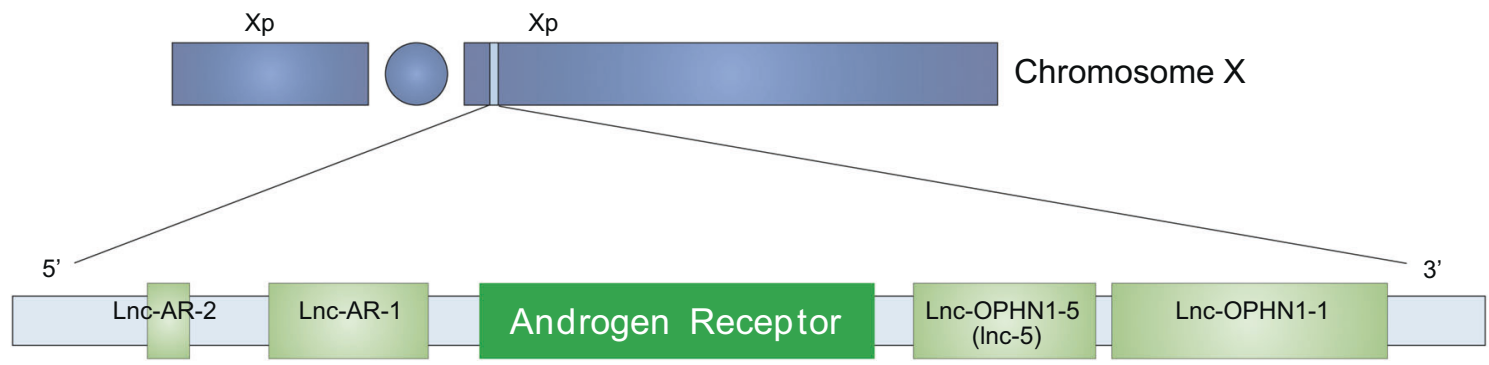

B

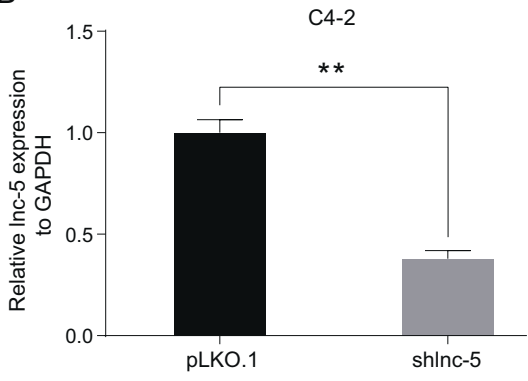

E

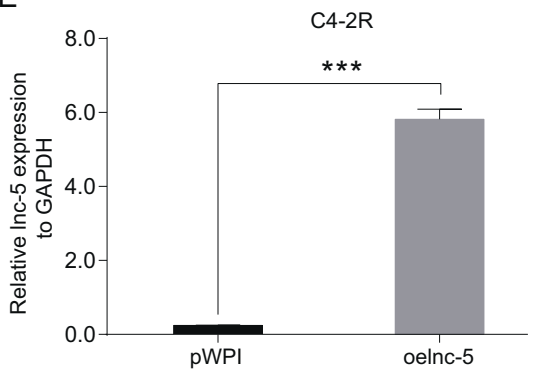

$\mathrm{H}$

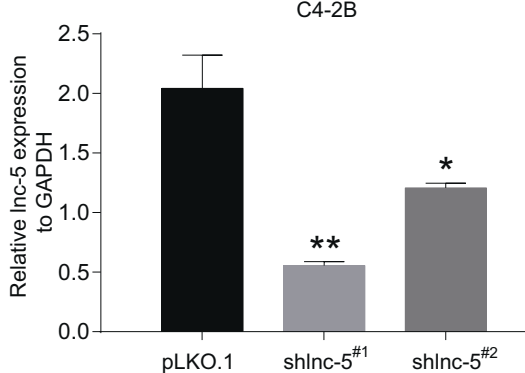

K

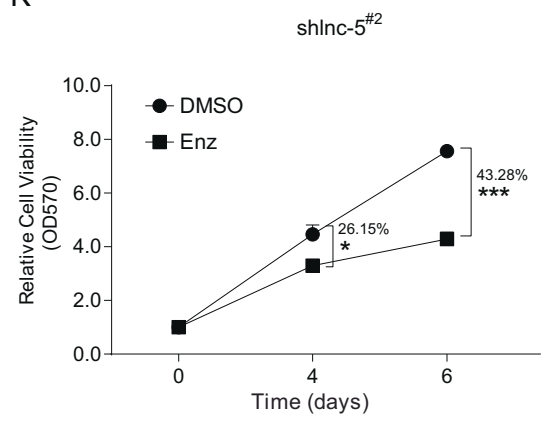

C

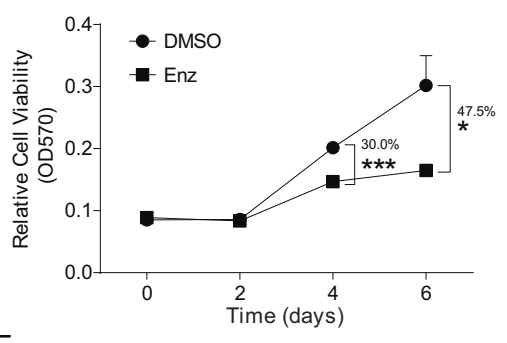

F

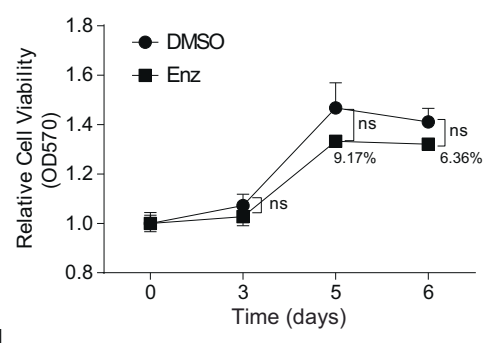

pLKO.1

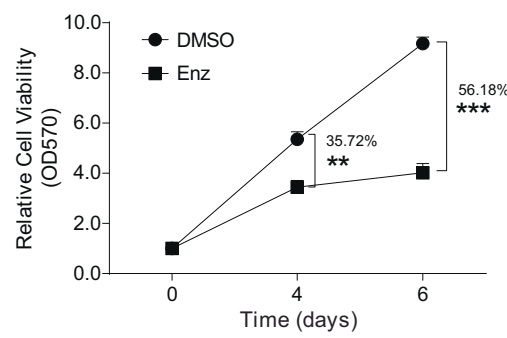

L

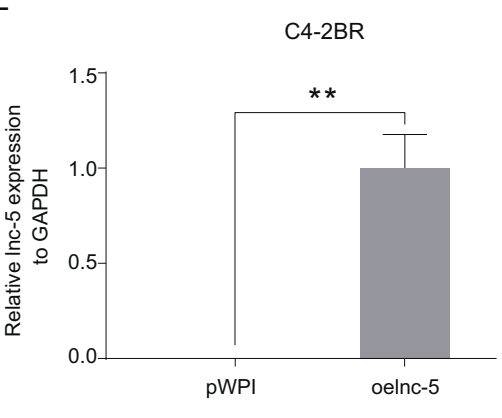

D

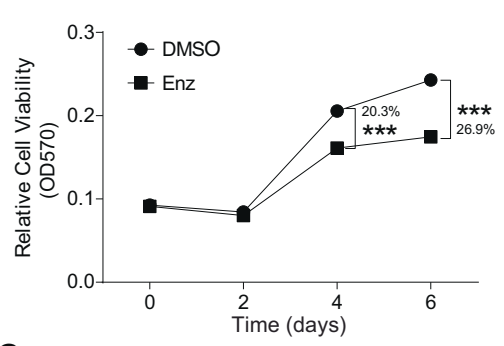

G

oelnc-5
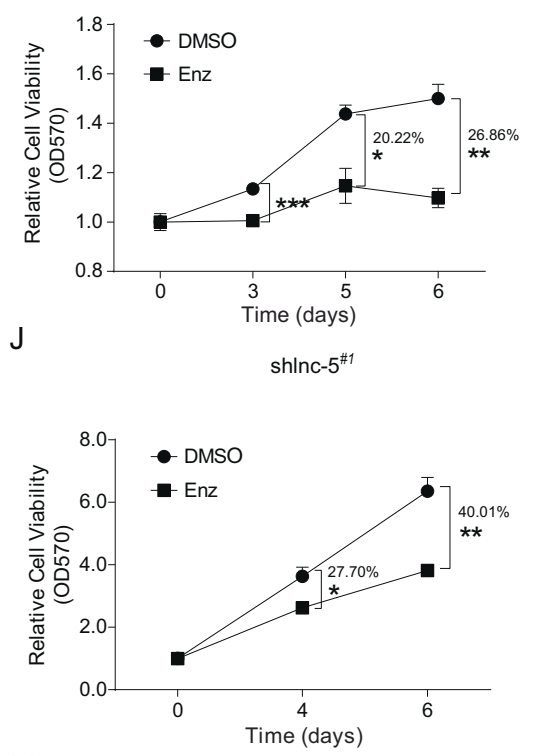

m

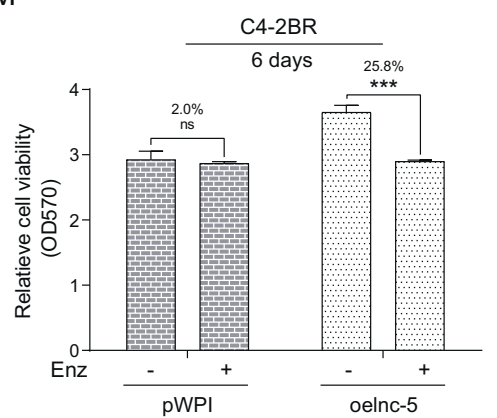

Fig. 1 The Inc-OPHN1-5 (Inc-5) influences prostate cancer (PCa) cell Enzalutamide (Enz) treatment sensitivity. A The model showed the location of IncRNAs surrounding AR on Chromosome X. B The knocking down efficiency of Inc-5 $5^{\# 2}$ (shlnc $-5^{\# 2}$ ) in C4-2 cells. C-D. Compared to pLKO.1 (C), shlnc-5 in C4-2 cells expression significantly decreased Enz treatment sensitivity (D) indicated by MTT assay. E. Ectopic Inc-5 (oelnc5) expression efficiency in C4-2R cells. F-G Compared to pWPI (F), oelnc-5 expression in C4-2R cells significantly increased Enz treatment sensitivity. G indicated by MTT assay. H Knock down efficiency of Inc-5 (shlnc-5 ${ }^{\# 1}$ and shlnc-5 ${ }^{\# 2}$ ) in C4-2B cells. I-K Compared to pLKO.1

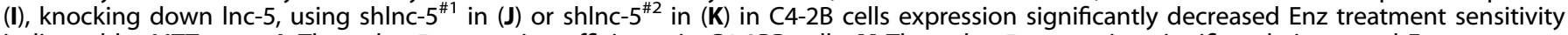

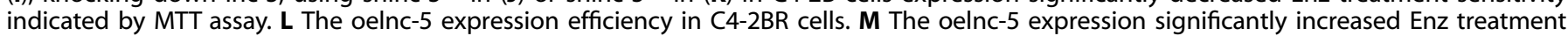
sensitivity in C4-2BR cells indicated by MTT assay. ${ }^{*} P<0.05 ;{ }^{*} P<0.01 ;{ }^{* *} P<0.001$; ns, no significant difference. 


\section{Statistical analysis}

The results for each treatment group were presented as a representative of multiple repeated experiments with each data point performed in triplicate. Statistical studies between the two groups were conducted using the two-tailed unpaired Student's $t$-test or non-parametric test (Mann-Whitney test) depending on the homogeneity test of variance. Data were presented as the mean and standard error of the mean (mean \pm SEM) or the mean+/-standard deviation (mean+/-SD) unless mentioned otherwise. A $P$-value $<0.05$ was considered statistically significant.

\section{RESULTS}

\section{Identifying Inc-OPHN1-5 as a regulator of Enz treatment} sensitivity in CRPC

Previous studies reported that aberrations of AR (including mutation, deletion, and amplification) are frequently found in PCa patients (Fig. S1) [27-29]. More recently, chromatin elements outside the AR locus have also been found to be able to contribute to the PCa progression via a long-distance transcriptional regulation of the AR gene [5]. These alterations likely will also influence the expression of genes, such as IncRNAs in close proximity of the AR locus, and whether their expression also contributes to the PCa progression, particularly resistance to the anti-androgen Enz is not known.

To examine their potential role in regulating AR activity, we found four IncRNAs, Inc-AR-1, Inc-AR-2, Inc-OPHN1-1, and IncOPHN1-5, which were $1 \mathrm{MB} 5^{\prime}$ and $3^{\prime}$ of AR on the $X$ chromosome (Fig. 1A) based on the LNCipedia database (https://Incipedia.org/). To implicate their potential role in PCa progression, we generated four short hairpin RNAs (shRNAs) to knock down their expression to test whether there is a IncRNA that could influence Enz treatment sensitivity. The results revealed one IncRNA, Inc-OPHN15 , whose silencing (sh), with two different shRNAs to eliminate offtarget effects, significantly decreased Enz treatment sensitivity in C4-2 cells (Fig. 1B-D; Figs. S2A and S3A-B). In contrast, overexpression (oe) of Inc-OPHN1-5 significantly increased Enz treatment sensitivity in C4-2R cells (Fig. 1E-G). Consistent results were generated when we replaced the C4-2/C4-2R cells with C42B/C4-2BR cells (Fig. $1 \mathrm{H}-\mathrm{M}$ ). In addition, we used the EdU staining assay to confirm the MTT data, and similar regulation of PCa Enz treatment sensitivity by Inc-OPHN1-5 was observed (Fig. S2B). The analysis of the potential protein-coding capacity indicated that
A

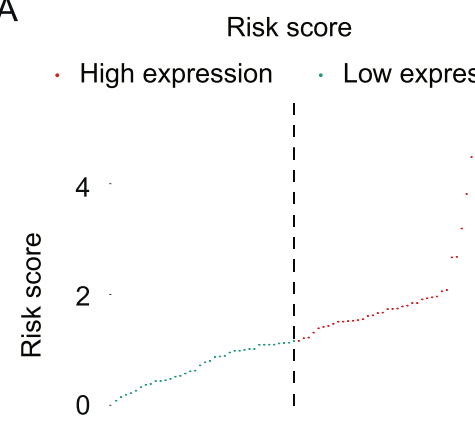

B
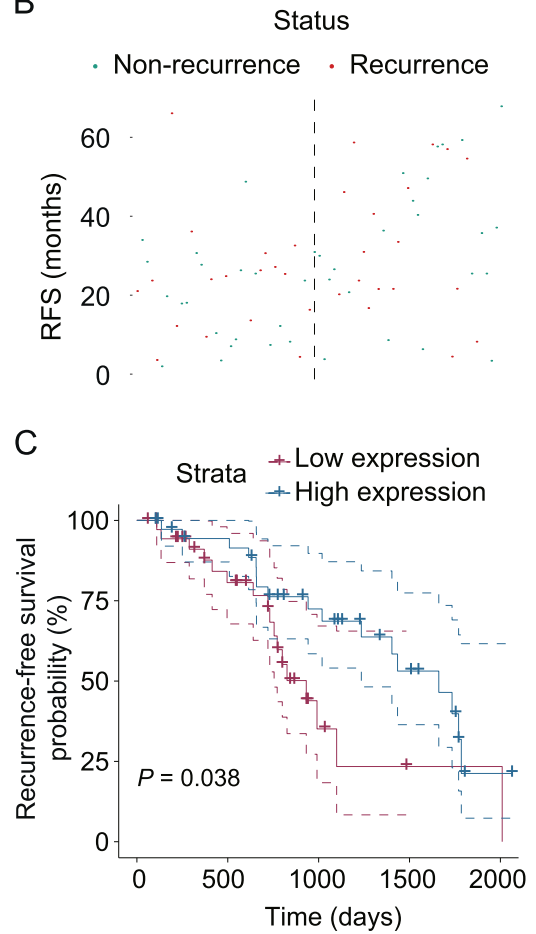

D

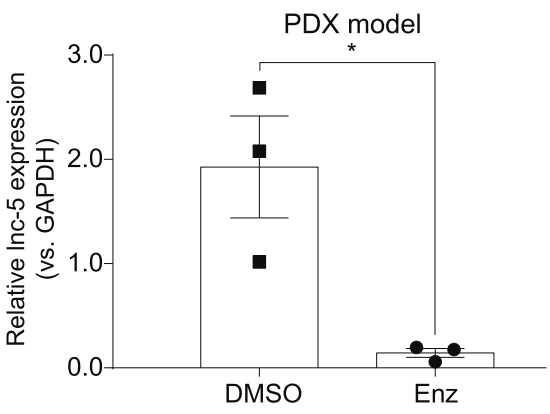

$\mathrm{E}$

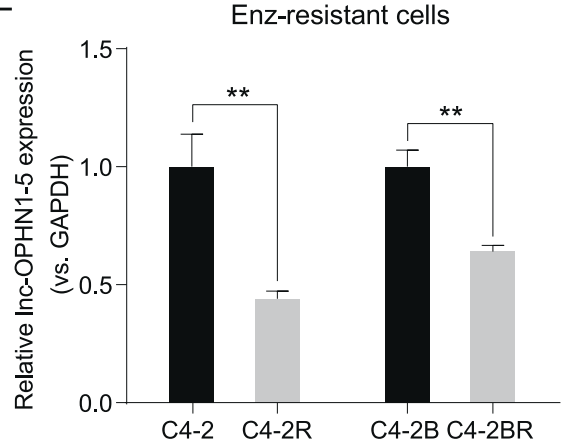

Fig. 2 Clinical values of Inc-OPHN1-5 (Inc-5) in prostate cancer (PCa). A Sorting the PCa samples by Inc-5 expression determined by reverse transcription-polymerase chain reaction (RT-PCR) assay. B Displaying the recurrent status of PCa patients in high- and low-Inc-5 expression subgroups. C Kaplan-Meier plot and log-rank analysis suggested that the patients with lower expression of Inc-5 had worse recurrence-free survival outcomes than those with higher Inc-5 expression. D The relative Inc-5 expression in patient-derived Xenograft (PDX) models after long-time Enzalutamide (Enz)-treatment compared with controls determined by RT-PCR assay. E The relative Inc-5 expression in C4-2R \& C42BR cells compared with parental C4-2 \& C4-2B cells determined by RT-PCR assay. ${ }^{*} P<0.05$; ${ }^{* *} P<0.01$. 
Inc-OPHN1-5 could not encode a protein (Fig. S3C). Since knowing the subcellular localization of IncRNAs will provide fundamental insights into their biological function and foster hypotheses for underlying mechanisms, we employed nuclear and cytoplasm fractionation assays and demonstrated that Inc-OPHN1-5 is located in both the nucleus and cytoplasm (Fig. S3D).
A

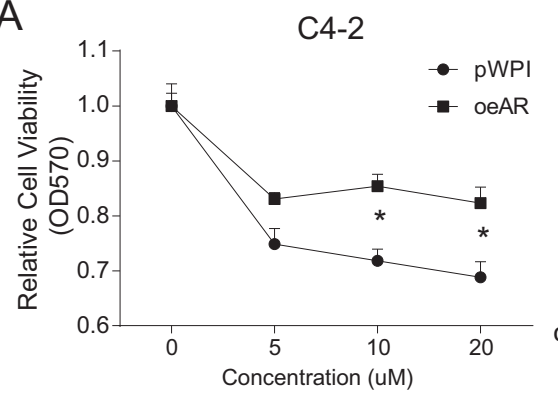

D

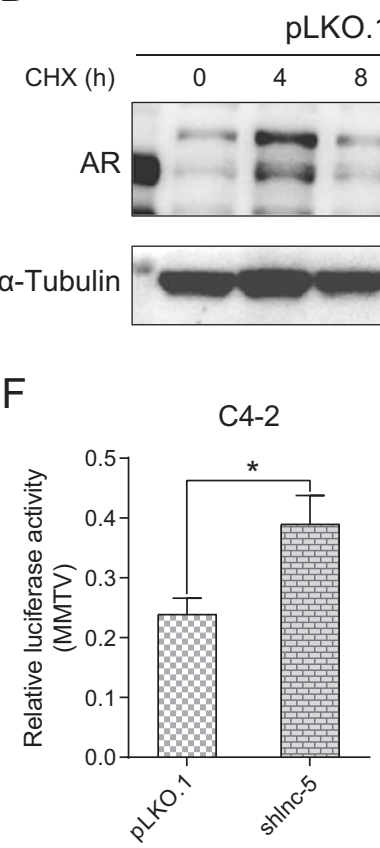

G
B

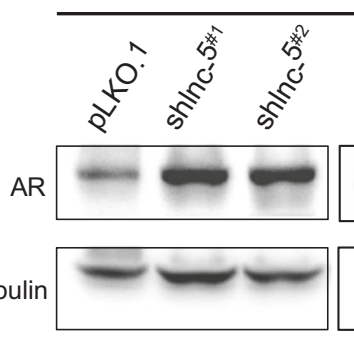

C
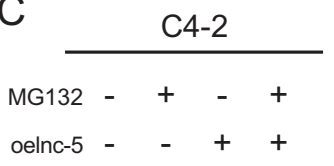

$J$

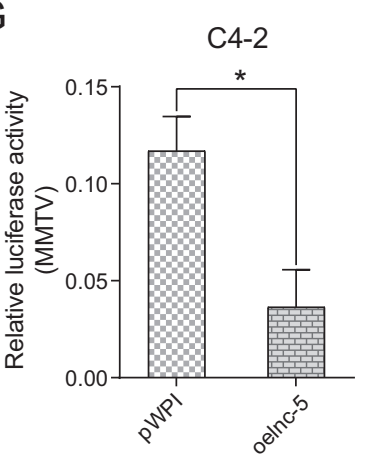

$\mathrm{H}$

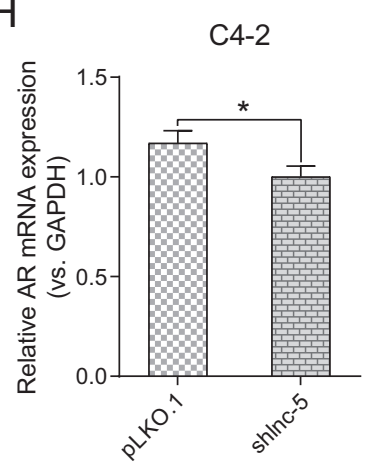

$\mathrm{E}$

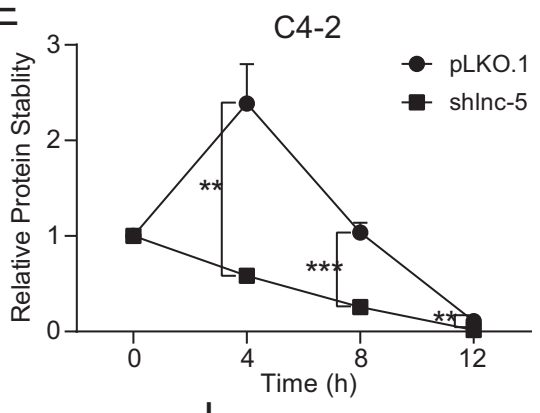

I

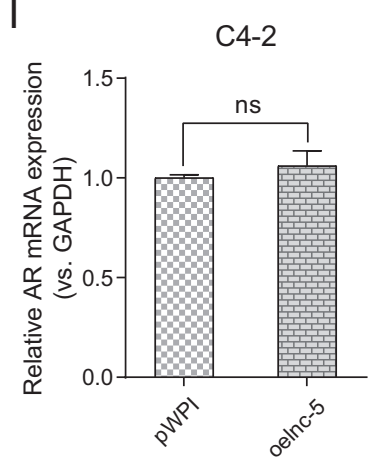

C4-2

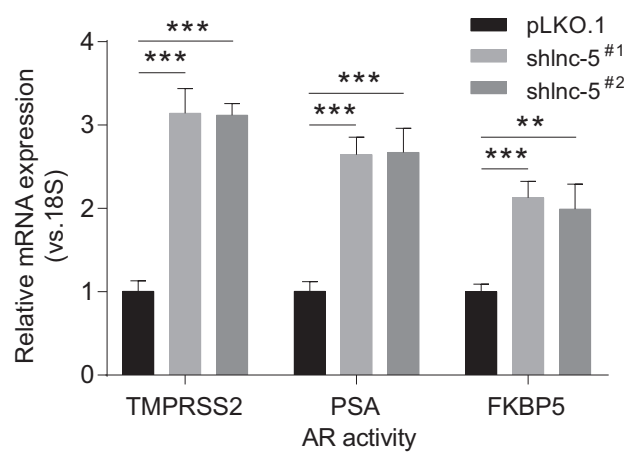

Fig. 3 The Inc-OPHN1-5 (Inc-5) influences AR protein expression and transcriptional activity independent of influencing its protein stability. A Ectopic AR (oeAR) expression decreased Enzalutamide (Enz) treatment sensitivity in C4-2 cells determined by MTT assay. B After manipulating Inc-5 expression in C4-2 cells, the influence of AR protein expression was determined by western blotting (WB) assay. C The influence of proteasome inhibitor MG132 on AR protein expression before and after ectopic Inc-5 (oelnc-5) expression determined by WB assay. D The stability variation of AR protein with or without cycloheximide (CHX) treatment in C4-2 cells with knock down of Inc-5 (shlnc-5) expression compared to pLKO.1 as determined by WB assay. E The quantification results of AR protein degradation after shlnc-5 expression. F, G Shlnc-5 expression increased AR transcriptional activity tested by MMTV-luciferase assay, which could be suppressed by oelnc-5 expression in C4-2 cells. H, I Reverse transcription-polymerase chain reaction (RT-PCR) assay showed that shlnc-5 expression slightly decreased AR mRNA expression, while oelnc-5 expression did not influence the AR mRNA expression, indicating that Inc-5 regulated AR protein expression independent of AR mRNA expression. J Shlnc-5 expression significantly increased the AR classic downstream PSA, TMPRSS2, and FKBP5 expression determined by RT-PCR assay. ${ }^{*} P<0.05$; ${ }^{* *} P<0.01$; ${ }^{* * *} P<0.001$; ns, no significant difference. 
To further determine the clinical significance of Inc-OPHN1-5, we tested its expression in clinical samples from PCa patients, Enzresistant cell lines, and PDX models. Consistent with its biological function, we found that lower expression of Inc-OPHN1-5 was significantly associated with unfavorable prognosis of PCa patients (Table S2 and Fig. 2A-C). As indicated in the PDX mouse model of human PCa samples, we found that after long-term Enz treatment, the expression of Inc-OPHN1-5 was significantly decreased (Fig. 2D), which was consistent with the finding in C4-2/C4-2R \& C4-2B/C4-2BR cells with long-term Enz treatment compared with their parental cells (Fig. 2E). We further applied the human clinical sample survey via Gene Expression Omnibus (GEO) dataset (GSE48403) analysis. Results revealed that in some PCa patients with a higher grade or higher Gleason score of $\mathrm{PCa}$, their IncOPHN1-5 expressions were decreased after ADT (three of seven patients decreased, Fig. S3E and Table S3), and in contrast, in some PCa patients with a lower grade or lower Gleason score of PCa, their Inc-OPHN1-5 expressions were increased after ADT (four of seven patients increased, Fig. S3E), indicating that ADT efficacy might be linked with Inc-OPHN1-5 expression.

Taken together from Figs. 1-2, Table S2-S3, and Fig. S1-S3, these data suggest that the patients with low expression of Inc-OPHN1-5 likely have unfavorable prognoses and are probably less sensitive to Enz treatment.

\section{The Inc-OPHN1-5 can alter AR protein expression and transcriptional activity}

Several studies suggested that IncRNAs participate in the regulation of epigenetic, transcription, post-transcription, translation, and post-translational modification processes [3032]. Since $A R$ and $A R$ signals have a significant impact on Enz treatment sensitivity $[33,34]$ and the Inc-OPHN1-5 is physically close to the Chromosome $\mathrm{X}$ on the $A R$ gene, we were interested in determining whether Inc-OPHN1-5 might function via altering AR expression or activity to regulate Enz sensitivity. Consistent with previous findings that $A R$ expression can directly impact Enz sensitivity (Fig. 3A), we found that knocking down Inc-OPHN1-5 increased AR protein expression (Fig. 3B), but failed to increase the protein stability (Fig. 3C-E). Ectopic Inc-OPHN1-5 expression decreased the AR protein expression (Fig. 3B). In addition, by applying the MMTV-luciferase promoter-reporter assay, we found that knocking down IncOPHN1-5 expression enhanced AR transactivation and increasing Inc-OPHN1-5 expression led to suppress AR transactivation (Fig. 3F, G). On a molecular level, the RT-PCR assay suggested that Inc-OPHN1-5 did not influence AR mRNA level (Fig. $3 \mathrm{H}, \mathrm{I}$ ), but the downstream genes, such as PSA, FKBP5, and TMPRSS2, were significantly increased after silencing the expression of this IncRNA (Fig. 3J).

Taken together, the results from Fig. 3 suggest that Inc-OPHN15 may alter the AR transactivation as well as AR protein expression, without influencing the $A R$ protein stability and AR mRNA expression.

\section{Mechanism dissection of how Inc-OPHN1-5 can decrease AR protein expression: via reducing $A R$ translation}

As shlnc-OPHN1-5 increased AR protein expression, yet failed to alter AR protein stability or mRNA expression, we tested whether AR mRNA translation was enhanced. To determine the association of AR mRNA with ribosomes, thus translation under the influence of Inc-OPHN1-5, we extracted the AR mRNA through biotin-labeled antisense AR oligonucleotide (Oligo), and examined the associated ribosome through the measurement of $18 \mathrm{~S}$ ribosomal RNA, and results revealed that knocking down IncOPHN1-5 expression led to significantly increase the abundance of ribosomes that were associated with AR mRNA, and increasing Inc-OPHN1-5 expression led to suppress their interaction (Fig. 4A, B).

Furthermore, in the ribosome fraction upon cellular organelle fractionation, we found that knocking down Inc-OPHN1-5 expression led to increasing the abundance of AR mRNA, while overexpressing Inc-OPHN1-5 expression decreased AR mRNA in the ribosome fraction (Fig. 4C, D respectively), consistent with the AR mRNA pull-down results. Taken together, the results from
A

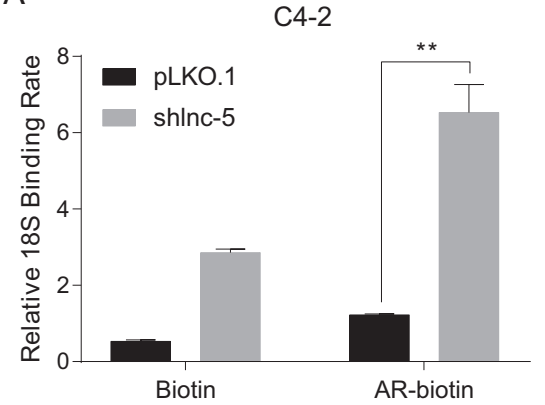

B

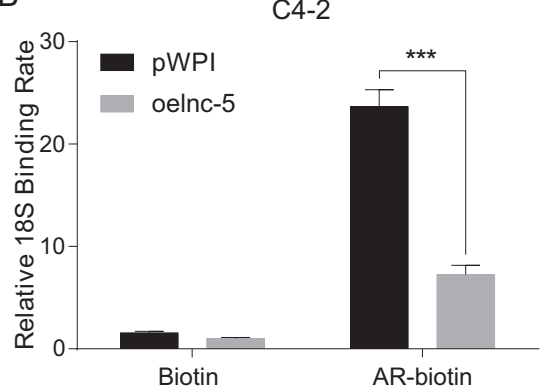

C

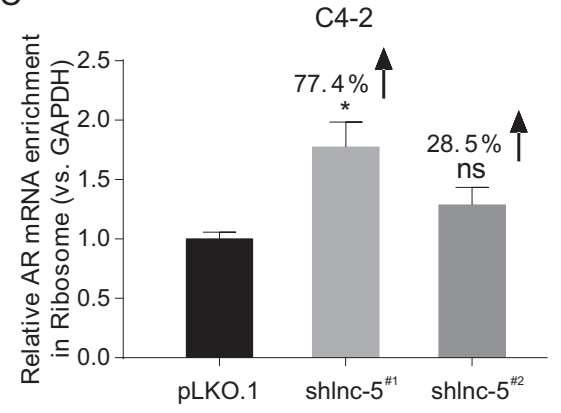

D

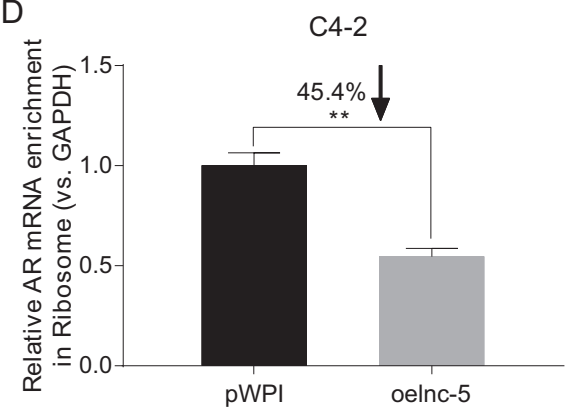

Fig. 4 The Inc-OPHN1-5 (Inc-5) expression influences the AR mRNA translation. A, B Knocking down Inc-5 expression (shlnc-5) increased the interaction between AR mRNA and $18 \mathrm{~S}(\mathrm{~A})$, while their interaction could be suppressed by ectopic Inc-5 (oelnc-5) expression in C4-2 cells by RNA immunoprecipitation (RIP) and reverse transcription-polymerase chain reaction (RT-PCR) assays (B). C Shlnc-5 expression increased the enrichment of AR mRNA in ribosome in C4-2 cells determined by RT-PCR assay. D Oelnc-5 expression decreased the enrichment of AR mRNA in ribosome in C4-2 cells determined by RT-PCR assay. ${ }^{*} P<0.05 ;{ }^{* *} P<0.01 ;{ }^{* *} P<0.001$; ns, no significant difference. 
Fig. 4, suggest that Inc-OPHN1-5 decreases AR protein expression potentially via reducing $A R$ protein translation.

Mechanism dissection of how Inc-OPHN1-5 reduces AR mRNA translation: via suppressing AR mRNA-hnRNPA1 interaction Recent studies indicated that mRNA translation could be influenced by mRNA's interaction with IncRNAs as well as RBPs $[14,35]$. Based on the published literature, we selected four common RBPs that have been found to be associated with $\mathrm{PCa}$, including hnRNPA1 [36], hnRNPA/B [37], hnRNPK [38], and HUR [39]. Indeed, we used biotin-labeled antisense oligos to pull-down the AR mRNA (AR-biotin) and its interacting molecules, including RNAs or proteins. As indicated in Fig. 5A, we found that AR mRNA was successfully pulled-down by AR-biotin, and we detected the presence of Inc-OPHN1-5, as well as the four RBPs mentioned above (Fig. 5B). As the previous study suggested that hnRNPA1 influences Enz treatment sensitivity [40], we chose hnRNPA1 as a representative for further investigation.

The RIP assay by pull-down of hnRNPA1 using its specific antibody was applied to detect whether knocking down (Fig. S4A) or increasing (Fig. S4B) Inc-OPHN1-5 expression influenced the interaction between hnRNPA1 and AR mRNA. These results suggested that knocking down Inc-OPHN1-5 increased the interaction between AR mRNA and hnRNPA1 (Fig. 5C), while their interaction was decreased after increasing Inc-OPHN1-5 expression (Fig. 5D). Similar results were also obtained while replacing the hnRNPA1 antibody with biotin-labeled antisense of AR mRNA (Fig. 5E, F).

Taken together, the data from Fig. 5 and Fig. S4A, B suggest that Inc-OPHN1-5 suppresses hnRNPA1-AR mRNA interaction, thus decreasing AR mRNA translation to decrease AR protein. Such a consequence may then lead to an increase in Enz treatment sensitivity.

\section{The Inc-OPHN1-5 competes with hnRNPA1 binding to $3^{\prime}$ UTR of AR mRNA to decrease its translation}

We found that Inc-OPHN1-5 directly interacted with the $3^{\prime} U T R$ of the AR mRNA (Table S4), according to the website prediction (https:// blast.ncbi.nlm.nih.gov/Blast.cgi?PROGRAM = blastn\&PAGE_TYPE = BlastSearch\&LINK_LOC = blasthome). To test whether this binding was critical for the Inc-OPHN1-5 function, we then constructed a mutant (mut) Inc-OPHN1-5 by deleting the presumptive AR-mRNA interaction regions (Fig. 6A). After ectopic expression of wild-type (wt) and mut-Inc-OPHN1-5, we found the mut-Inc-OPHN1-5 failed to
A

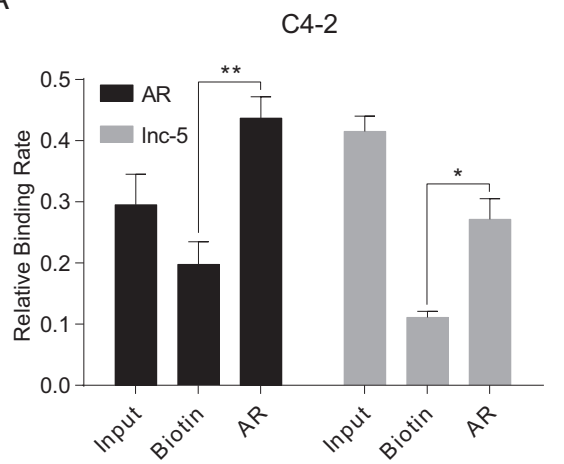

C

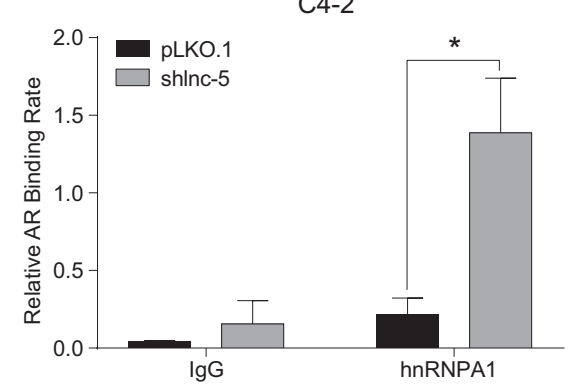

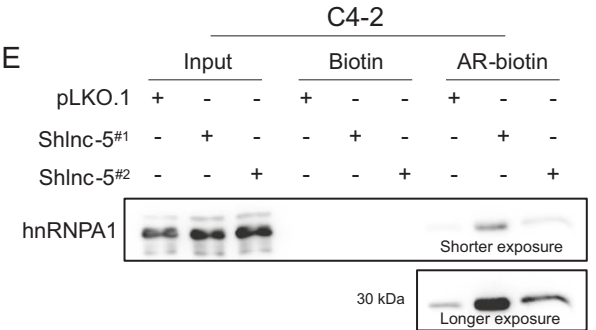

B

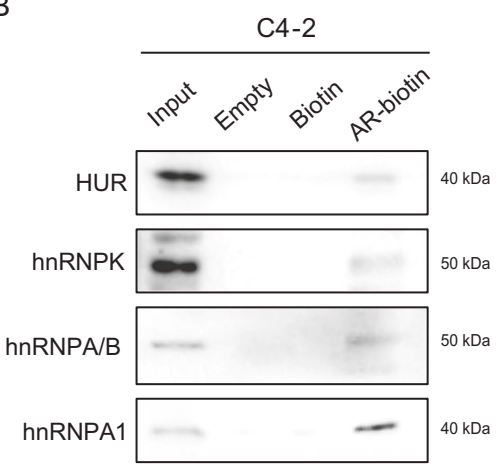

D

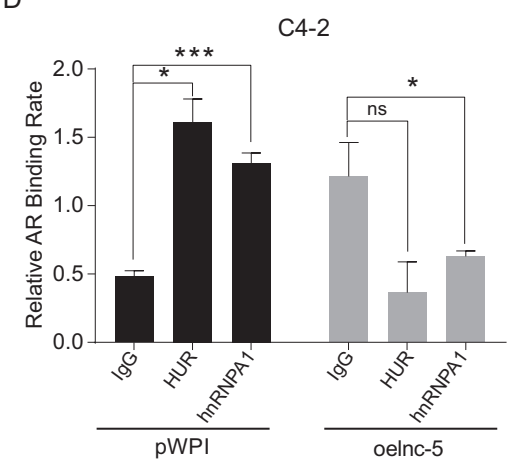

$\mathrm{F}$

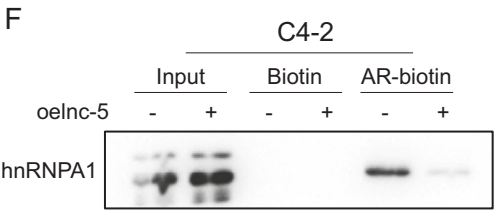

Fig. 5 The Inc-OPHN1-5 (Inc-5) influences the AR mRNA interaction with RNA-binding protein (RBP) hnRNPA1 and ribosome RNA 185. A RNA immunoprecipitation (RIP) assay by pull-down of AR mRNA using its specific biotin showed that AR directly interacted with Inc-5 in C42 cells determined by reverse transcription-polymerase chain reaction (RT-PCR). B RIP and western blotting (WB) assays showed that AR mRNA directly interacted with four RBPs, including hnRNPA1, HUR, hnRNPK, and hnRNPA/B. C, D RIP assay by pull-down of hnRNPA1 showed that knocking down Inc-5 (shlnc-5) increased the interaction between AR mRNA and hnRNPA1 (C) while their interaction could be suppressed (D) by ectopic Inc-5 (oelnc-5) expression in C4-2 cells determined by RT-PCR assay. E, F RIP assay by pull-down of AR mRNA biotin showed that shlnc-5 (with shlnc- $5^{\# 1}$ and shlnc- $5^{\# 2}$ ) increased the interaction between AR mRNA and hnRNPA1 while their interaction could be suppressed by oelnc- 5 expression in C4-2 cells determined by RIP and WB assays. ${ }^{*} P<0.05 ;{ }^{* *} P<0.01,{ }^{* * *} P<0.001$; ns, no significant difference. 
significantly decrease the enrichment of AR mRNA in the ribosome, as well as the interaction between AR mRNA and $18 \mathrm{~S}$ ribosomal RNA compared with the wt-Inc-OPHN1-5 (Fig. 6B, C). In addition, RIP and western blotting assays revealed that only wt-lnc-OPHN1-5 effectively suppressed AR mRNA-hnRNPA1 interaction (Fig. 6D) and AR protein expression (Fig. 6 E and Fig. S4C), thus significantly increased Enz treatment sensitivity, while the mut IncRNA had less capacity to do so (Fig. 6F).

Taken together, the data from Fig. 6, Table S4, and Fig. S4C, suggest that Inc-OPHN1-5 competes with hnRNPA1 binding to 3'UTR of AR mRNA to decrease its translation and protein level.

\section{Preclinical studies with multiple PCa in vitro cell lines and in vivo mouse model demonstrate that targeting the Inc- OPHN1-5/AR/hnRNPA1 complex with shhnRNPA1 leads to increase Enz treatment sensitivity to better suppress $\mathrm{PCa}$ progression}

To link our above studies to potential clinical applications, we were interested in applying small molecule(s) to target this newly identified Inc-OPHN1-5/AR/hnRNPA1 complex to increase the Enz treatment sensitivity, thus better suppress the PCa progression. We first applied the shhnRNPA1 to reverse/block the Inc-OPHN1-5 increased AR protein expression (Fig. 7A). The results revealed that adding shhnRNPA1 increased Enz treatment sensitivity in C4-2 and C4-2B cells (Fig. 7B, C).

We further examined whether the Inc-OPHN1-5 could influence the Enz treatment sensitivity or tumor growth in the in vivo mice model. C4-2 cells were lentivirally infected with pLKO.1 and shlncOPHN1-5 constructs. These cells $(3 \times 106)$ were mixed with Matrigel $(1: 1, v / v)$ and subcutaneously injected into the left hind limb of the NCG male mice at six weeks of age. Two months later, we found that only two if 12 mice formed tumors in the pLKO.1 group $(2 / 11,18.2 \%)$, while 11 of 12 mice developed tumors in the shlnc-OPHN1-5 group $\left(11 / 12,91.7 \%, X^{2}=9.798, P=0.0017\right)$ (Fig. 7D, mice images, and $E$, tumor formation rates). Further analyses found no significant difference in tumor volumes (Fig. 7F) and tumor weights (Fig. 7G) between the two groups, using Mann-Whitney tests, $P>0.05$. The RT-PCR assay found that the expression of Inc-OPHN1-5 was significantly lower in the tumors of the shlnc-OPHN1-5 group compared with vector controls (Mann-Whitney tests, $P<0.05$, Fig. 7l). The AR mRNA expression was conversely higher (Fig. $7 \mathrm{H})$, but lack statistical significance according to Mann-Whitney tests, $P=0.0714$. In addition, IHC analysis showed that AR protein was higher in tumors with the expression of the shlnc-OPHN1-5 group (Fig. 7J) compared with vector control (Fig. 7K), using Mann-Whitney tests, $P<0.05$.

Taken together, the data from Figs. 1-7, Tables S1-S4, and Figs. S1-4 suggest that Inc-OPHN1-5 interacts with the specific region of $A R$ mRNA $3^{\prime} U T R$, reducing the latter's interaction with RBP-hnRNPA1, thus decreasing AR mRNA translation and protein expression. Targeting this newly identified Inc-OPHN15/AR/hnRNPA1 complex with a small molecule like shhnRNPA1 could then lead to an increase in Enz sensitivity to better suppress PCa progression. A cartoon was made to illustrate the study (Fig. 8).

\section{DISCUSSION}

Enz has been in clinical use to extend MCRPC patients' survival an extra 4.8 months [2-4]. However, most patients still succumb after the development of Enz-resistance. Currently, several mechanisms have been proven to be involved in the Enz-resistance in CRPC, including induction of altered glucocorticoid receptor [41], AKT signals [42-44], AR-v7 expression [45], and AR (F876L) mutations [46-48]. In addition, enhanced AR protein levels or signals also have been proven to lead to Enz-resistance [7, 34].

Han et al. [34] found that Triptolide suppresses AR binding to the promoter regions of the AR target genes. In addition, the low dose of Triptolide enhances the anti-androgen Enz efficacy on CRPC xenografts with minimal side effects. In Takeda et al.'s work [7], they characterize a somatically acquired AR enhancer located $650 \mathrm{~kb}$ centromeric to the AR. Systematic perturbation of this enhancer decreases AR protein expression, decreasing cell viability through a genome editing method, while inserting an additional copy of this region increases PCa cell proliferation under lowandrogen conditions and compromises Enz efficacy. Both of these
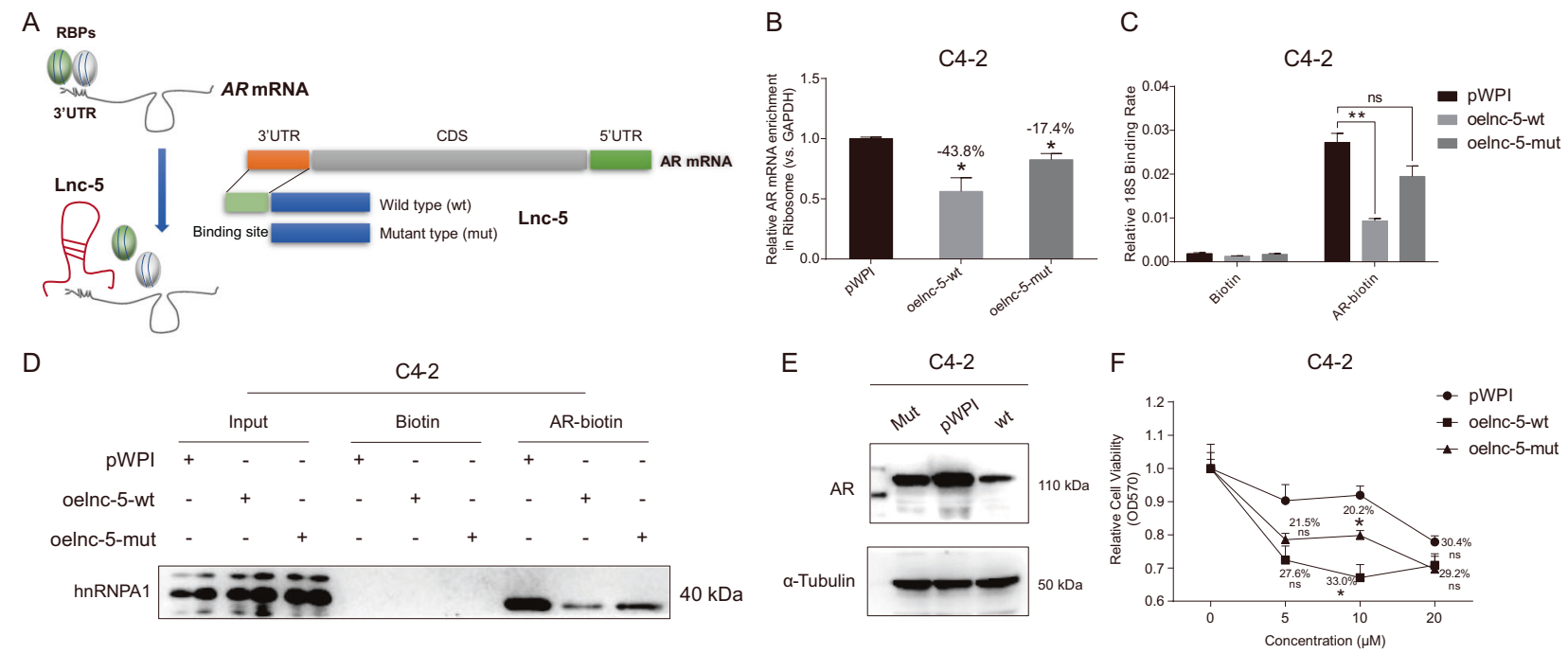

Fig. 6 The Inc-OPHN1-5 (Inc-5) binding to the specific region of AR mRNA to influence its translation, protein expression, and Enzalutamide (Enz) treatment sensitivity. A The cartoon shows the construction of a mutant (mut)-Inc-5 by deleting the AR mRNA-binding site. B The influence of ectopic wild type wt/mut-Inc-5 (oelnc-5-wt, oelnc-5-mut) expression on the enrichment of AR mRNA in ribosomes in C4-2 cells determined by reverse transcription-polymerase chain reaction (RT-PCR) assay. C The influence of oelnc-5-wt/mut expression on the interaction between AR mRNA and $18 \mathrm{~S}$ in C4-2 cells determined by RT-PCR assay. D The influence of oelnc-5-wt/mut expression on the interaction between AR mRNA and hnRNPA1 in C4-2 cells determined by western blotting (WB) assay. E The influence of oelnc-5-wt/mut expression on AR protein levels in C4-2 cells determined by WB assay. $\mathbf{F}$ The influence of oelnc-5-wt/mut expression on Enz treatment sensitivity in C4-2 cells determined by MTT assay. ${ }^{*} P<0.05 ;{ }^{* *} P<0.01$; ${ }^{* *} P<0.001$; ns, no significant difference; RBP, RNA binding protein; UTR, untranslated regions. 
studies suggested that enhanced AR level and signal activity are among the mechanisms for Enz treatment resistance.

Thus, we hypothesized that there might exist some IncRNAs that are located surrounding the $A R$ gene on chromosome $X$, and these
IncRNAs potentially have a role on AR function. Notably, we found that only Inc-OPHN1-5 suppresses AR expression and associates with enhanced Enz treatment sensitivity. In addition, evidence from resistant cell lines, the PDX mouse models, PCa tissues, and a human
A

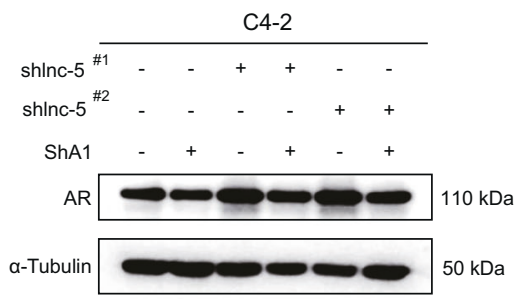

D

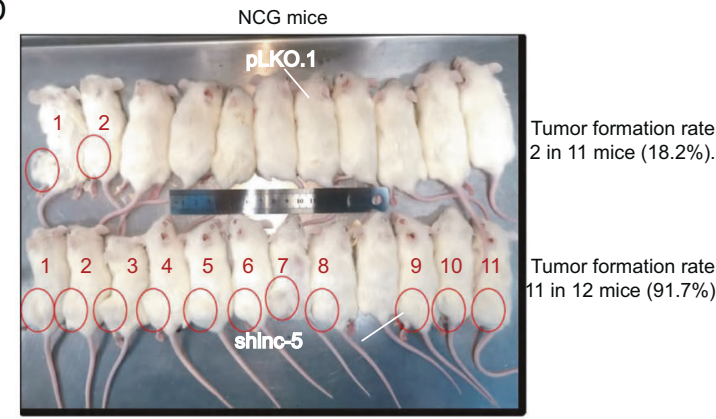

E

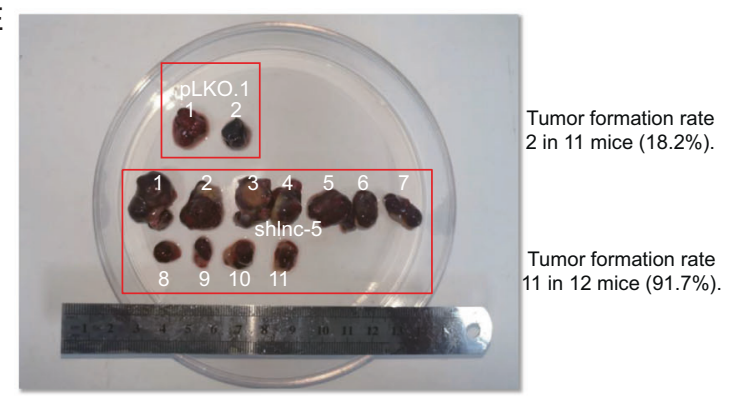

$\mathrm{J}$

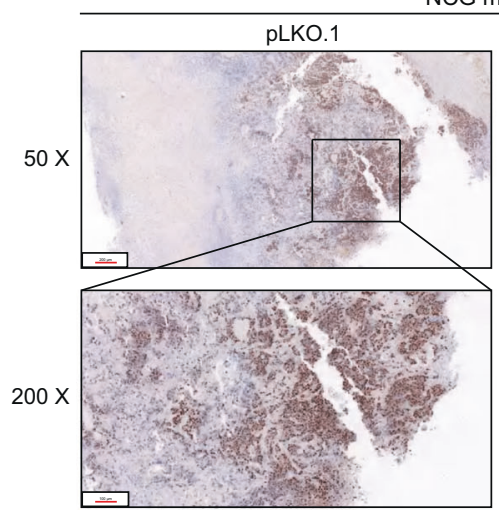

B

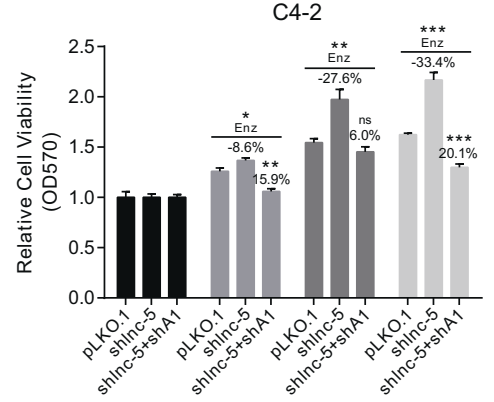

$\mathrm{F}$
C

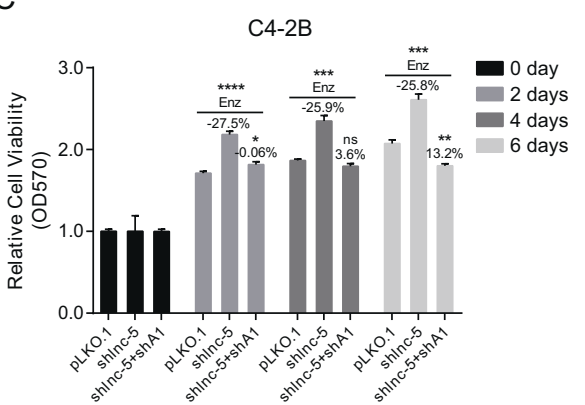

G

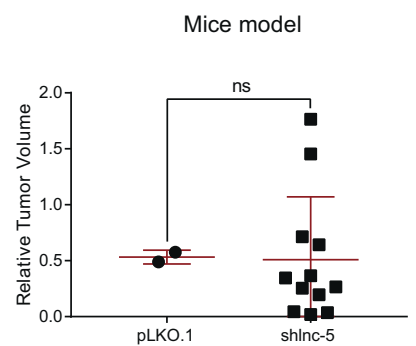

$\mathrm{H}$

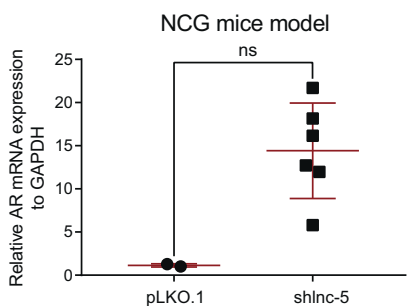

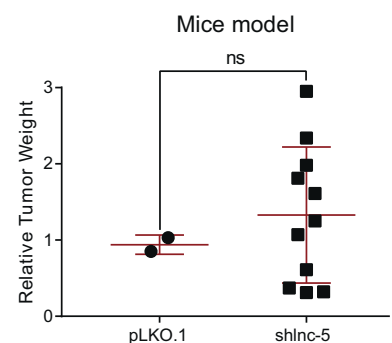

I

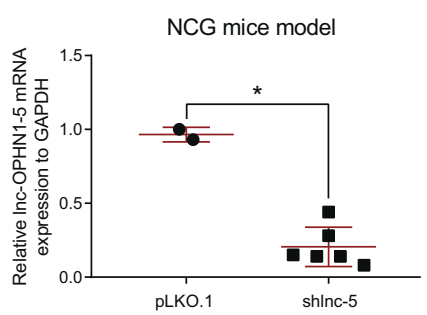

$\mathrm{K}$
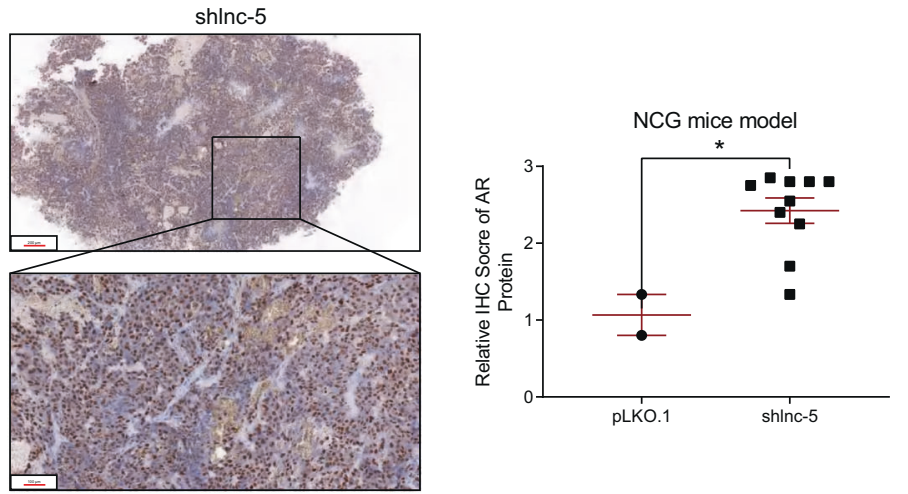

Fig. 7 Targeting the Inc-OPHN1-5 (Inc-5)/AR/hnRNPA1 complex with shhnRNPA1 led to increasing Enzalutamide (Enz)-treatment sensitivity and in vivo evidence of Inc-5's function in prostate cancer (PCa). A Knocking down hnRNPA1 (shhnRNPA1) expression reversed silencing Inc-5 (shlnc- $5^{\# 1}$ and shlnc $-5^{\# 2}$ ) expression induced AR up-regulation in C4-2 cells determined by western blotting (WB) assay. B-C. ShhnRNPA1 expression re-sensitized shlnc-5 caused PCa Enz-resistance in C4-2 (B) and C4-2B cells determined by MTT assay (C). D, E Display of the mice images (D) and formed tumors $(\mathbf{E})$ in vector and shlnc-5 subgroups. $\mathbf{F}$, $\mathbf{G}$ The comparison of tumor volumes $(\mathbf{F})$ and tumor weights (G) between the shlnc-5 and vector subgroups. H, I Reverse transcription-polymerase chain reaction (RT-PCR) results showing the expression of $A R(\mathbf{H})$ and Inc-5 (I) between the shlnc-5 and vector subgroups. J, $\mathbf{K}$ Immunohistochemistry (IHC) assay showing the AR protein expression between the shlnc-5 and vector subgroups (J), and the immunohistochemistry (IHC) scores were also quantified $(\mathbf{K})$. ${ }^{*} P<0.05 ;{ }^{*} P<0.01$; ${ }^{* * *} P<0.001$; ns, no significant difference; NCG mice, NOD CRISPR Prkdc II2r Gamma triple-immunodeficient mice. 


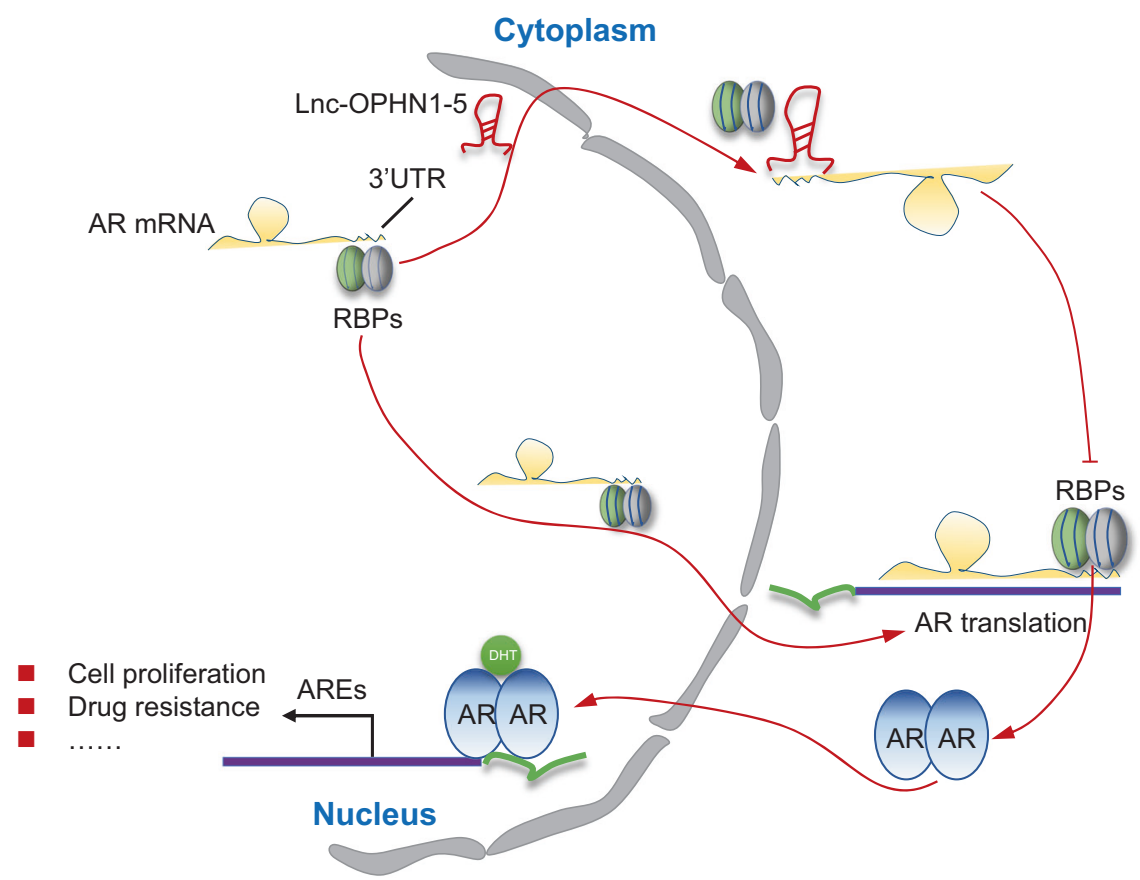

Fig. 8 Schematic model. The Inc-OPHN1-5 (Inc-5) directly interacts with AR mRNA, reducing AR mRNA interaction with RNA binding proteins (RBPs), thus decreasing AR mRNA translation, protein expression, and transcriptional activity, enhancing Enzalutamide (Enz) treatment sensitivity. ARE, androgen receptor response element; UTR, untranslated region.

PCa study all indicated that PCa patients with low expression of IncOPHN1-5 likely have unfavorable prognoses and probably are less sensitive to Enz treatment. Consistently, our in vivo data shows a vast difference in tumor formation rate between the vector group and shlnc-OPHN1-5 group (18.2\% vs. $\left.91.7 \%, X^{2}=9.798, P=0.0017\right)$, further supporting the notion that the expression of Inc-OPHN1-5 is negatively associated with PCa patients' poor prognosis. The mechanism study found that the Inc-OPHN1-5 directly interacts with the AR mRNA, reducing the interaction between AR mRNA and hnRNPA1, therefore, suppresses the AR mRNA translation and protein synthesis, enhancing the Enz treatment sensitivity. Consistent with that, knocking down hnRNPA1 reverses shlnc-OPHN1-5 induced AR protein expression and re-sensitizes cells to Enz treatment.

The involvement of hnRNPA1 in mRNA splicing has been recognized for a long time $[49,50]$, but its role in regulating the translational process has only recently been appreciated [51-53]. During tumor development, several oncogenes and tumor promoters are translationally controlled by hnRNPA1, including FGF-2, cMYC, CCND1, XIAP, BCL-XL $[52,54,55]$, etc. Nadiminty et al. [40] found that silencing hnRNPA1 and consequently of AR-v7 resensitizes cells to Enz treatment, indicating that upregulation of hnRNPA1 may confer resistance to anti-androgen therapies by promoting expression of the AR variants. However, we found that silencing Inc-OPHN1-5 expression did not influence the AR-v7 expression. Notably, we found that hnRNPA1 is involved in the IncOPHN1-5 mediated AR mRNA translation process. Ectopic IncRNA expression significantly suppresses the interaction between $A R$ mRNA and hnRNPA1, thus decreases AR protein expression. The opposite phenomenon was observed when we knocked down IncOPHN1-5 expression. These conclusions were supported by the AR mRNA abundance in the ribosomal fraction as well as ribosomal RNA level in the AR mRNA pull-down assay using biotin-conjugated antisense oligos. Furthermore, our results also found that knocking down hnRNPA1 decreases shlnc-OPHN1-5 induced AR protein increase and re-sensitizes C4-2 cells to Enz treatment. Altogether with the previous report, our data suggested that Inc-OPHN1-5 is a part of the complex regulation of AR protein expression involving the hnRNPA1-mediated mRNA translation.
One weakness of our work is that we did not provide evidence to demonstrate the Enz sensitivity in the mice xenograft model due to the inefficiency, therefore no statistical power of tumor formation with the parental cells. Similarly, clinical samples from the existing GEO dataset are limited to provide statistical power to support our hypothesis that low expression of Inc-OPHN1-5 links to unfavorable Enz treatment response. More clinical samples before and after Enz treatment are needed to test this hypothesis in PCa patients rigorously. In addition, since Enz treatment sensitivity might be influenced by cell growth rates at a certain timepoint, in our case, the cell growth could be slightly decreased by the Inc-OPHN1-5 expression. The caveat notwithstanding we have the evidence to support the role of Inc-OPHN1-5 from clinical samples, in vivo mice models, and PDX xenograft models, we still need more evidence to rigorously demonstrate that its impact on Enz treatment sensitivity of PCa is not derived from its minor impact on cell proliferation.

In summary, we characterized a novel IncRNA, Inc-OPHN1-5, which influences anti-androgen Enz treatment sensitivity by decreasing AR mRNA translation and protein synthesis. Targeting the Inc-OPHN1-5/hnRNPA1/AR axis represents a potential strategy for the treatment of CRPC.

\section{DATA AVAILABILITY}

The data used and/or analyzed during the current study are available from the corresponding author on reasonable request.

\section{REFERENCES}

1. Siegel RL, Miller KD, Jemal A. Cancer Statistics, 2017. Ca A Cancer J Clinicians. 2017:67:5-30.

2. Tran C, Ouk S, Clegg NJ, Chen Y, Watson PA, Arora V, et al. development of a second-generation anti-androgen for treatment of advanced prostate cancer. Science. 2009;324:787-90.

3. Ryan CJ, Smith MR, de Bono JS, Molina A, Logothetis CJ, de Souza P, et al. Abiraterone in metastatic prostate cancer without previous chemotherapy. $\mathrm{N}$ Engl J Med. 2013;368:138-48. 
4. Beer TM, Armstrong AJ, Rathkopf DE, Loriot $\mathrm{Y}$, Sternberg CN, Higano CS, et al. Enzalutamide in metastatic prostate cancer before chemotherapy. N Engl J Med. 2014;371:424-33.

5. Quigley DA, Dang HX, Zhao SG, Lloyd P, Aggarwal R, Alumkal JJ, et al. Genomic hallmarks and structural variation in metastatic prostate. Cancer Cell. 2018;174:758-69 e759.

6. Gandhi J, Afridi A, Vatsia S, Joshi G, Joshi G, Kaplan SA, et al. The molecular biology of prostate cancer: current understanding and clinical implications. Prostate Cancer Prostatic Dis. 2018;21:22-36.

7. Takeda DY, Spisak S, Seo JH, Bell C, O'Connor E, Korthauer K, et al. A somatically acquired enhancer of the androgen receptor is a non-coding driver in advanced prostate. Cancer Cell. 2018;174:422-32 e413.

8. Zhuo W, Liu Y, Li S, Guo D, Sun Q, Jin J, et al. Long non-coding RNA GMAN, upregulated in gastric cancer tissues, is associated with metastasis in patients and promotes translation of ephrin $\mathrm{A} 1$ by competitively binding GMAN-AS. Gastroenterology. 2019;156:676-91.

9. Kopp F, Mendell JT. Functional classification and experimental dissection of long noncoding RNAs. Cell. 2018;172:393-407.

10. Ivan M, Kaelin WG Jr. The EGLN-HIF O2-sensing system: multiple inputs and feedbacks. Mol Cell. 2017;66:772-9.

11. Khalil AM, Guttman M, Huarte M, Garber M, Raj A, Rivea Morales D, et al. Many human large intergenic non-coding RNAs associate with chromatin-modifying complexes and affect gene expression. Proc Natl Acad Sci USA. 2009;106:11667-72.

12. Gupta RA, Shah N, Wang KC, Kim J, Horlings HM, Wong DJ, et al. Long non-coding RNA HOTAIR reprograms chromatin state to promote cancer metastasis. Nature. 2010;464:1071-6.

13. Lin $C$, Wang $Y$, Wang $Y$, Zhang $S$, Yu L, Guo $C$, et al. Transcriptional and posttranscriptional regulation of HOXA13 by IncRNA HOTTIP facilitates tumorigenesis and metastasis in esophageal squamous carcinoma cells. Oncogene. 2017;36:5392-406.

14. Yoon $\mathrm{JH}$, Abdelmohsen $\mathrm{K}$, Gorospe $M$. Posttranscriptional gene regulation by long non-coding RNA. J Mol Biol. 2013;425:3723-30.

15. Zhou B, Wang $Y$, Jiang J, Jiang $H$, Song J, Han $T$, et al. The long non-coding RNA colon cancer-associated transcript-1/miR-490 axis regulates gastric cancer cell migration by targeting hnRNPA1. IUBMB Life. 2016;68:201-10.

16. Wang J, Yang W, Chen $Z$, Chen J, Meng Y, Feng B, et al. Long noncoding RNA IncSHGL recruits hnRNPA1 to suppress hepatic gluconeogenesis and lipogenesis. Diabetes. 2018;67:581-93.

17. Zhang M, Sun Y, Meng J, Zhang L, Liang C, Chang C. Targeting AR-beclin 1 complex-modulated growth factor signaling increases the antiandrogenenzalutamide sensitivity to better suppress the castration-resistant prostate cancer growth. Cancer Lett. 2019;1442:483-90.

18. Niu Y, Yeh S, Miyamoto H, Li G, Altuwaijri S, Yuan J, et al. Tissue prostate-specific antigen facilitates refractory prostate tumor progression via enhancing ARA70regulated androgen receptor transactivation. Cancer Res. 2008;68:7110-9.

19. Tian J, Lee SO, Liang L, Luo J, Huang CK, Li L, et al. Targeting the unique methylation pattern of androgen receptor (AR) promoter in prostate stem/progenitor cells with 5-aza-2'-deoxycytidine (5-AZA) leads to suppressed prostate tumorigenesis. J Biol Chem. 2012;287:39954-66.

20. Masse T, Garcin D, Jacquemont B, Madjar JJ. Ribosome and protein synthesis modifications after infection of human epidermoid carcinoma cells with herpes simplex virus type 1. Mol Gen Genet. 1990;220:377-88.

21. Madjar JJ, Nielsen-Smith K, Frahm M, Roufa DJ. Emetine resistance in chinese hamster ovary cells is associated with an altered ribosomal protein S14 mRNA. Proc Natl. Acad Sci USA. 1982;79:1003-7.

22. Chen J, Li L, Yang Z, Luo J, Yeh S, Chang C. Androgen-deprivation therapy with enzalutamide enhances prostate cancer metastasis via decreasing the EPHB6 suppressor expression. Cancer Lett. 2017;408:155-63.

23. Brehm MA, Cuthbert A, Yang C, Miller DM, Dilorio $P$, Laning J, et al. Parameters for establishing humanized mouse models to study human immunity: analysis of human hematopoietic stem cell engraftment in three immunodeficient strains of mice bearing the IL2rgamma(null) mutation. Clin Immunol. 2010;135:84-98.

24. Izumi K, Mizokami A, Lin WJ, Lai KP, Chang C. Androgen receptor roles in the development of benign prostate hyperplasia. Am J Pathol. 2013;182:1942-9.

25. Huang CP, Chen J, Chen CC, Liu G, Zhang Y, Messing E, et al. ASC-J9(R) increases the bladder cancer chemotherapy efficacy via altering the androgen receptor (AR) and NF-kappaB survival signals. J Exp Clin Cancer Res. 2019;38:275.

26. Xiao Y, Sun Y, Liu G, Zhao J, Gao Y, Yeh S, et al. Androgen receptor (AR)/miR-520f$3 \mathrm{p} / \mathrm{SOX} 9$ signaling is involved in altering hepatocellular carcinoma (HCC) cell sensitivity to the Sorafenib therapy under hypoxia via increasing cancer stem cells phenotype. Cancer Lett. 2019;444:175-87.

27. Lallous N, Volik SV, Awrey S, Leblanc E, Tse R, Murillo J, et al. Functional analysis of androgen receptor mutations that confer anti-androgen resistance identified in circulating cell-free DNA from prostate cancer patients. Genome Biol. 2016;17:10.
28. Brooke GN, Bevan CL. The role of androgen receptor mutations in prostate cancer progression. Curr Genomics. 2009;10:18-25.

29. Eisermann K, Wang D, Jing Y, Pascal LE, Wang Z. Androgen receptor gene mutation, rearrangement, polymorphism. Transl Androl Urol. 2013;2:137-47.

30. Dykes IM, Emanueli C. Transcriptional and post-transcriptional gene regulation by long non-coding RNA. Genomics Proteom Bioinforma. 2017;15:177-86.

31. Vance KW, Ponting CP. Transcriptional regulatory functions of nuclear long noncoding RNAs. Trends Genet. 2014;30:348-55.

32. Heo JB, Lee YS, Sung S. Epigenetic regulation by long non-coding RNAs in plants. Chromosome Res. 2013;21:685-93.

33. Soekmadji C, Rockstroh A, Ramm GA, Nelson CC, Russell PJ. Extracellular vesicles in the adaptive process of prostate cancer during inhibition of androgen receptor signaling by enzalutamide. Proteomics. 2017;17. https://doi.org/10.1002/ pmic.201600427.

34. Han Y, Huang W, Liu J, Liu D, Cui Y, Huang R, et al. Triptolide inhibits the AR signaling pathway to suppress the proliferation of enzalutamide resistant prostate cancer cells. Theranostics. 2017;7:1914-27.

35. Bazin J, Baerenfaller K, Gosai SJ, Gregory BD, Crespi M, Bailey-Serres J. Global analysis of ribosome-associated non-coding RNAs unveils new modes of translational regulation. Proc. Natl. Acad. Sci. USA. 2017;114:E10018-27.

36. Tummala R, Lou W, Gao AC, Nadiminty N. Quercetin targets hnRNPA1 to overcome enzalutamide resistance in prostate cancer cells. Mol. Cancer Ther. 2017;16:2770-9.

37. He Y, Brown MA, Rothnagel JA, Saunders NA, Smith R. Roles of heterogeneous nuclear ribonucleoproteins A and B in cell proliferation. J. Cell Sci. 2005;118:3173-83.

38. Ciarlo M, Benelli R, Barbieri O, Minghelli S, Barboro P, Balbi C, et al. regulation of neuroendocrine differentiation by $\mathrm{AKT} / \mathrm{hnRNPK/AR/beta-catenin} \mathrm{signaling} \mathrm{in}$ prostate cancer cells. Int J. Cancer. 2012;131:582-90.

39. Epis MR, Barker A, Giles KM, Beveridge DJ, Leedman PJ. The RNA-binding protein HuR opposes the repression of ERBB-2 gene expression by microRNA miR-331-3p in prostate cancer cells. J. Biol. Chem. 2011;286:41442-54.

40. Nadiminty N, Tummala R, Liu C, Lou W, Evans CP, Gao AC. NF-kappaB2/p52:c-Myc hnRNPA1 pathway regulates expression of androgen receptor splice variants and enzalutamide sensitivity in prostate cancer. Mol. Cancer Ther. 2015;14:1884-95.

41. Arora VK, Schenkein E, Murali R, Subudhi SK, Wongvipat J, Balbas MD, et al. Glucocorticoid receptor confers resistance to anti-androgens by bypassing androgen receptor blockade. Cell. 2013;155:1309-22.

42. Luo Y, Azad AK, Karanika S, Basourakos SP, Zuo X, Wang J, et al. Enzalutamide and CXCR7 inhibitor combination treatment suppresses cell growth and angiogenic signaling in castration-resistant prostate cancer models. Int J. Cancer. 2018;142:2163-74.

43. Toren P, Kim S, Johnson F, Zoubeidi A. Combined AKT and MEK pathway blockade in pre-clinical models of enzalutamide-resistant prostate cancer. PLoS ONE. 2016;11:e0152861.

44. Toren P, Kim S, Cordonnier T, Crafter C, Davies BR, Fazli L, et al. Combination AZD5363 with enzalutamide significantly delays enzalutamide-resistant prostate cancer in preclinical models. Eur Urol. 2015;67:986-90.

45. Antonarakis ES, Lu C, Wang $\mathrm{H}$, Luber B, Nakazawa M, Roeser JC, et al. AR-V7 and resistance to enzalutamide and abiraterone in prostate cancer. $\mathrm{N}$ Engl $\mathrm{J}$ Med. 2014;371:1028-38.

46. Joseph JD, Lu N, Qian J, Sensintaffar J, Shao G, Brigham D, et al. A clinically relevant androgen receptor mutation confers resistance to second-generation anti-androgens enzalutamide and ARN-509. Cancer Discov. 2013;3:1020-9.

47. Korpal M, Korn JM, Gao X, Rakiec DP, Ruddy DA, Doshi S, et al. An F876L mutation in androgen receptor confers genetic and phenotypic resistance to MDV3100 (enzalutamide). Cancer Discov. 2013;3:1030-43.

48. Wang R, Lin W, Lin C, Lei L, Yin S, Chang C. ASC-J9 ๑; suppresses castration resistant prostate cancer progression via degrading the enzalutamide-induced androgen receptor mutant AR-F876L. Cancer Lett. 2016;379:154-60.

49. Mayeda A, Krainer AR. Regulation of alternative pre-mRNA splicing by hnRNP A1 and splicing factor SF2. Cell. 1992;68:365-75.

50. Del Gatto-Konczak F, Olive M, Gesnel MC, Breathnach R. hnRNP A1 recruited to an exon in vivo can function as an exon splicing silencer. Mol Cell Biol. 1999;19:251-60.

51. Bevilacqua E, Wang X, Majumder M, Gaccioli F, Yuan CL, Wang C, et al. elF2alpha phosphorylation tips the balance to apoptosis during osmotic stress. J Biol Chem. 2010;285:17098-111.

52. Lewis SM, Veyrier A, Hosszu Ungureanu N, Bonnal S, Vagner S, Holcik M. Subcellular relocalization of a trans-acting factor regulates XIAP IRES-dependent translation. Mol Biol Cell. 2007;18:1302-11.

53. Cammas A, Pileur F, Bonnal S, Lewis SM, Lévêque N, Holcik M, et al. Cytoplasmic relocalization of heterogeneous nuclear ribonucleoprotein $\mathrm{A} 1$ controls translation initiation of specific mRNAs. Mol Biol Cell. 2007;18:5048-59.

54. Mahajan MC, Narlikar GJ, Boyapaty G, Kingston RE, Weissman SM. Heterogeneous nuclear ribonucleoprotein $\mathrm{C} 1 / \mathrm{C} 2, \mathrm{MeCP} 1$, and SWI/SNF form a chromatin remodeling complex at the beta-globin locus control region. Proc Natl Acad Sci USA. 2005;102:15012-7. 
12

55. Jo OD, Martin J, Bernath A, Masri J, Lichtenstein A, Gera J. Heterogeneous nuclear ribonucleoprotein $\mathrm{A} 1$ regulates cyclin D1 and c-myc internal ribosome entry site function through Akt signaling. J Biol Chem. 2008;283:23274-87.

\section{ACKNOWLEDGEMENTS}

We thank Karen Wolf for help editing the manuscript. This work was supported by George Whipple Professorship Endowment, and The National Natural Science Foundation of China 81630019 and 81802827 . Scientific Research Foundation of the Institute for Translational Medicine of Anhui Province (2017ZHYX02). The Natural Science Foundation of Guangdong Province, China (2017A030313800).

\section{AUTHOR CONTRIBUTIONS}

Study conception and design: $\mathrm{CL}, \mathrm{CC}$, and YS; data collection: $\mathrm{MZ}, \mathrm{C}-\mathrm{PH}$, and JL; analysis and interpretation of results: $M Z$, and JM; draft manuscript preparation: MZ, YS, and LZ. All authors reviewed the results and approved the final version of the manuscript.

\section{COMPETING INTERESTS}

The authors declare no competing interests.

\section{ETHICS APPROVAL}

The Ethics Committee of Anhui Medical University \& The First Affiliated Hospital of Anhui Medical University approved the ethics of the current study.

\section{INFORMED CONSENT}

The informed consent was obtained from the involved patients when they were in hospital for regular visits.

\section{ADDITIONAL INFORMATION}

Supplementary information The online version contains supplementary material available at https://doi.org/10.1038/s41419-021-03966-4.

Correspondence and requests for materials should be addressed to C.L. or C.C.

Reprints and permission information is available at http://www.nature.com/ reprints

Publisher's note Springer Nature remains neutral with regard to jurisdictional claims in published maps and institutional affiliations.
Open Access This article is licensed under a Creative Commons Attribution 4.0 International License, which permits use, sharing, adaptation, distribution and reproduction in any medium or format, as long as you give appropriate credit to the original author(s) and the source, provide a link to the Creative Commons license, and indicate if changes were made. The images or other third party material in this article are included in the article's Creative Commons license, unless indicated otherwise in a credit line to the material. If material is not included in the article's Creative Commons license and your intended use is not permitted by statutory regulation or exceeds the permitted use, you will need to obtain permission directly from the copyright holder. To view a copy of this license, visit http://creativecommons. org/licenses/by/4.0/.

(c) The Author(s) 2021 